\title{
THE LOCATION, HOUSE, OR NEIGHBOURHOOD CHOICE PREFERENCES AMONG MALAYSIAN HOUSING GENERATIONS
}

\author{
Hafiszah Ismail $^{1 *}$ and Shazwan Mohamed Shaari ${ }^{2}$ \\ ${ }^{1}$ Centre of Studies for Estate Management, Faculty of Architecture, Planning and Surveying, \\ Universiti Teknologi MARA (UiTM), 40450 Shah Alam, Selangor, Malaysia \\ ${ }^{2}$ Fakulti Alam Bina, Universiti Malaysia Sarawak, 94300 Kota Samarahan, Sarawak, Malaysia \\ E-mail: *hafiszah@uitm.edu.my,msshazwan@unimas.my
}

\begin{abstract}
Demographics and population have been evidenced as part of the key elements that affect property development. Changes in demographics specifically may influence the economy including the property market hence influences the generations. Behaviour and values divergences among various age groups (generations) resulted in a variance of housing choices and decisions made. The generations are the population categorised by the age cohort including the Baby Boomers, Generation X (Gen-X), Generation Y (Gen-Y) and Generation Z (Gen-Z). This study aims to offer a comprehensive overview of housing decisions via choices made between location, house, and neighbourhood between Malaysian generations. This study uses mixed methods approaches with the Selangor state as a case study. The Pairwise and Analytic Hierarchy Process (AHP) methods of data analyses used for consumer behavioural decision-making studies were adopted in this study to determine the preferences of future housing choice between location, house and neighbourhood. The analysis uncovers house, location and neighbourhood as the prime housing choices factors of the Malaysian generations. The findings evidenced likeliness and differences of housing decision by generations on the choices made. Most importantly, the findings are significant in contributing better understanding and grant indications to the local authorities and housing developers on the main attraction factors of housing choice preferred by generations that may be very valuable for the enhancement of future Malaysian housing provisions.
\end{abstract}

Keywords: Consumer Behaviour, Housing Decision, Housing Choice, Baby Boomers, Gen-X, Gen-Y, Gen-Z

\section{INTRODUCTION}

Divergences between age groups or the generational differences are widely debated in numerous issues focusing on generations. The distinct decision of choices made by different age groups or generations reflects their differences of needs, wants and preferences and this includes the divergence found in housing choice made by each generation. According to Bujang et. al. (2010), housing is being perceived by certain people as a shelter solely in fulfilling each person fundamental needs. In general, people perceive housing as the biggest distinct lifetime investment and considered one primary consumer product. The buyer behaviour is a study related to the consumer decision-making process on choices made from between alternatives of products and on the motive for the decision made to the final choice. The initial housing decision is on choosing whether to own or to rent. The next decision then is on the considerations of preferred choices between location, house, or neighbourhood. Once households have reached a considerably accepted socio-economic status, the choice of location of the house and neighbourhood is considered to be important (Zyed et. al., 2016). In relation, housing developers are one of the main suppliers of housing as products offered in the property market. They are the main actor in the supply side of the housing. The housing consumers are the people searching for housing or the party of the demand side of the housing market. According to Tan and Khong (2012), the mismatch between delivered housing characteristics and potential homebuyer resulted in the high number of unsold properties in the local housing market hence the discrepancy between housing supply and housing demand. 
Thorough studies on housing were therefore required, particularly by generations, to narrow the gap between mismatch and thus provide effective housing arrangements. In continuance, the meaning of residential (housing) environment features may be studied from a different perspective; quality, satisfaction, or preference (Zwartz and Coolen, 2006). For example, the hierarchical and multi-factorial evaluation system for residential environment satisfaction by $\mathrm{Ge}$ et. al. (2006). It elaborates that residential environment satisfaction is influenced effectively by convenience, safety, amenity, healthy and community features. Hence, this study aims to offer a comprehensive overview of the housing decision of the Malaysian generations by focussing on the future housing choice preferences mainly between location, house or neighbourhood. The primary results will show how preferences vary between generations or by age group. The main objectives of this study are; (i) To classify generations; (ii) To describe housing decisions and choice; and (iii) To compare the housing decisions and choices between the Malaysian generations.

\section{LITERATURE REVIEW}

\subsection{The fundamental needs of housing and the generations defined}

Housing is more than just a shelter (Ademiluyi, 2010). House may also be perceived as an asset that has been noted to be linked with other means of life that includes economic, social and educational needs. Parallel to Golubchikov and Badyina (2012), housing is the principal social situation that defines individuals and places the quality of life and welfare. Where buildings are situated, how well they are constructed and designed, and how well they are shaped into the setting, social, cultural and economic fabrics of societies are characteristics that influence people's everyday life in a manner. Housing, according to Golubchikov and Badyina (2012), is the fundamental social condition that defines the quality of life and welfare of the people and places. Where houses are located, how well they are built and designed, and how well they are modelled into the environment, social, cultural and economic fabrics of communities are attributes that in a way affect the daily lives of people, their security, health and wellbeing.

Due to its durability, price and variety, housing is therefore exclusive and distinct from other fundamental requirements, which can be handed over to generations (Skaburskis, 2002). Certain housing market criteria contrasted housing as a distinctive type of product heterogeneously with no focal market. To make it work, housing markets interrelate with other parts. The market which is not in equilibrium with the actors of the property development as the initiators will not have comprehensive details. Lack of required information would result in the buyers tend to be rarely being rational and hence would affect challenges in anticipating the market changes.

The theme of demographics and housing has been widely examined and widely debated by studies however less discussion was put into an emphasis on the matter the same matter in specific by generations or by particular age group. The populations are the generations or group of people identified according to their year born or based on the age cohorts. Therefore, the generations in this study; The Baby Boomers (born 1946-1961), Generation X (Gen-Z) (born 1962-1976), Generation Y (Gen-Y) (born 1977-1991) and Generation Z (Gen-Z) (born after 1992) were based on the classification by Reed and Conisbee (2006). The correlation investigations between population and housing by Mulder (2206) reveals that population changes will further lead to changing demand for housing as each generation is equipped with own characteristics. This would then make different generations resembles different needs, preferences and choices.

\subsection{Consumer decision-making behaviour and the housing decision}

The consumer behaviour explores not only the behaviours of consumers reveal but also the reasons for those behaviours. According to Gajjar (2013), the behaviour of consumers linked to the choice, purchase, and consumption of goods and services in fulfilling and satisfying their wants. Much of the study of consumer behaviour focuses on consumer choice. The five-stage model of consumer behaviour decision-making implies five (5) stages of decisionmaking before a decision was finally made; (i) need recognition; (ii) information search; (iii) evaluation of alternatives; (iv) purchase decision; and (v) postpurchase behaviour. The five-stage model implies that the buying process commences earlier before the actual purchase and consequences extensive afterwards (Kotler, 2012). The hypothesis made is that a purchase act is led by a sequence of mental information processing. This comprises a cognitive function in forming beliefs, an emotional component in developing positive or negative attitudes, and a reaction through being motivated to decide. Understanding housing buyer behaviour demands detail knowledge on the housing consumers' buying decisions or how considerations of the housing choices were made. Besides, the two (2) prime factors that influencing the consumer decision-making process are; (1) the individual (personal); and (2) the social factors. When accessing alternatives, such as choosing which property to buy or rent, consumers choose from 
a list of acceptable alternatives (induced or consideration set) based on the criteria they have selected as being important. Perceptions, beliefs and attitudes, values, learning, and personality were the individual (personal) factors that motivate consumer and this varies to each person. All interactions between consumer and the external environment including family, opinion leaders, social class and culture were examples of social factors that affect the decision-making process. Families are the key attribute in buying decisions (Dodoo, 2007). Majority of the products are purchased by the family unit rather than individuals. Family members are the most dominant role as it may play influential roles, such as verifying the financing and functional attributes of purchases, or they may act of expressive roles, supporting other family members in their decision expressing the family's aesthetic or emotional needs. Social, cultural, personal and psychological were the other influencing factors shaping the purchases of the consumers.

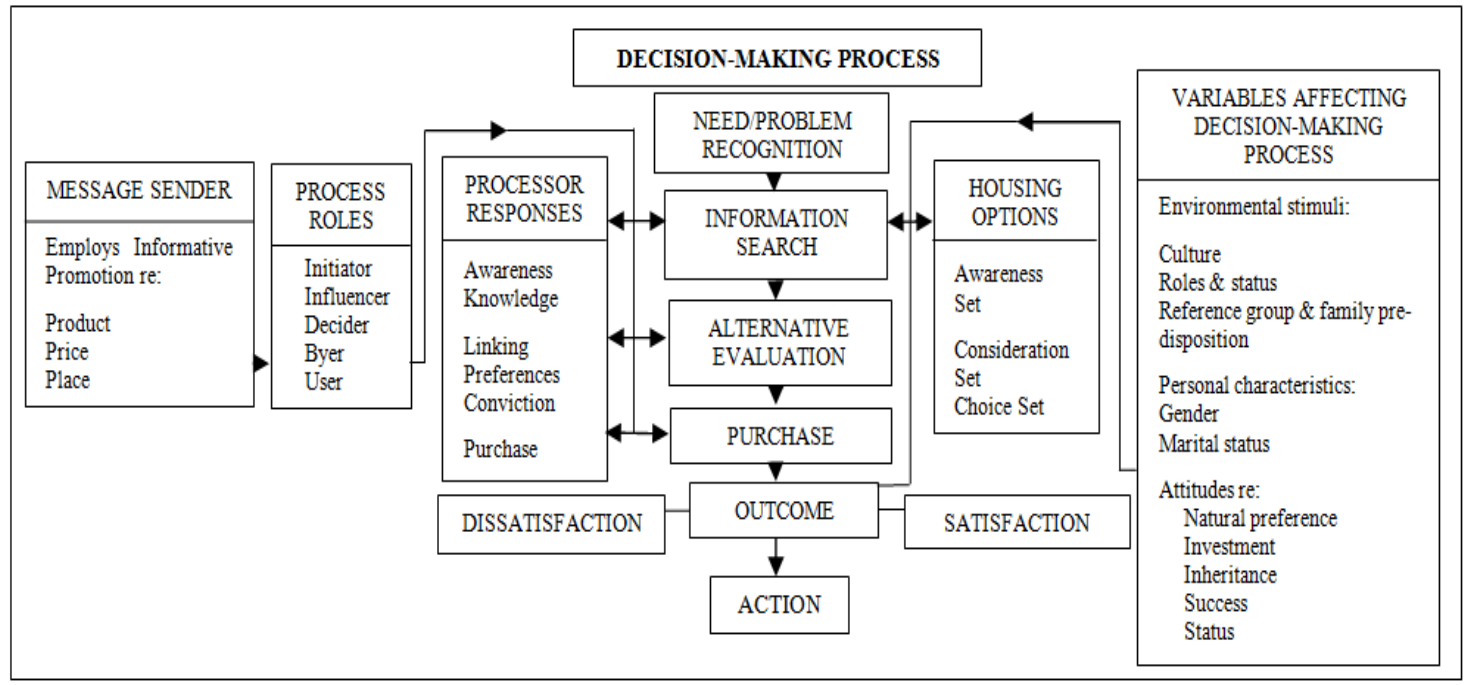

Figure 1: Housing-Buyer Behaviour Model

Source: Livette (2006)

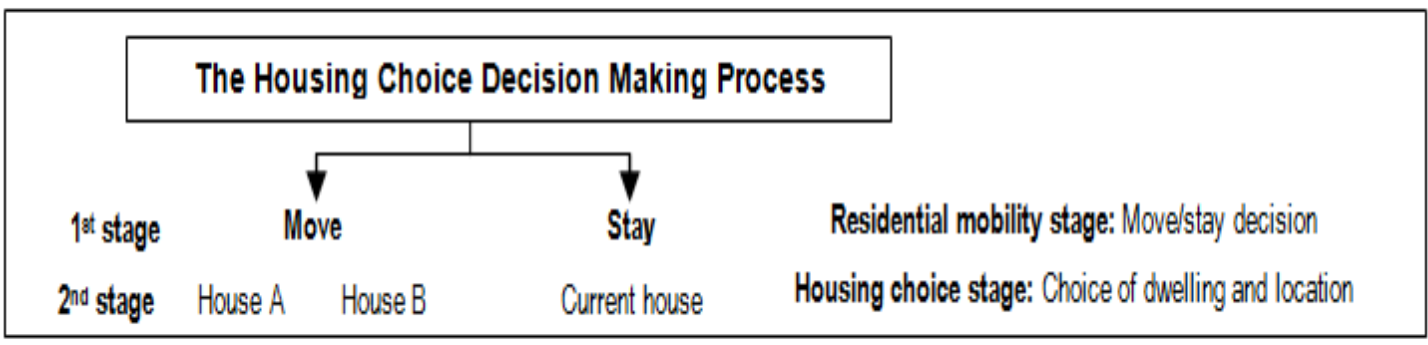

Figure 2: The Decision-Making Process of Housing Choice

Source: Kim et. al., (2005)

Consumer behaviour is also an eminent factor to indicate the decision-making process of house buying. A basic decision-making process for housing-buyer behaviour model by Livette (2006) encompasses the steps (from the left) (Figure 1) helps us to have a simple understanding of the housing buyer behaviour.

The complex and contingent household's housing decision-making process drives to varieties of methods used in evaluating the housing decision process of housing choice. Kim et. al., (2005), categorises the housing decisions into two (2) main stages. The first stage is the Residential Mobility stage which is the decision on whether to move or stay. The second stage is the Housing Choice stage which includes residential search and choice of a new residence (Figure 2).

\subsection{The housing decision: choice of preferences between house, location or neighbourhood?}

Housing location, dwelling characteristics and neighbourhood characteristics are the prime factors of preferences that required to critically explore and analyse to narrow the gap between supply and demand for housing or mismatch in the property market. Several studies emphasise the important role of the housing features namely dwelling, locational and neighbourhood attributes that would affect housing selection (Wang \& Li, 2006; Hurtubia et. 
al., 2010; Lachman, 2010; Tan, 2012). The housing selection or housing choice stage associates to the essential variables that would affect the housing consumer's current and future housing preferences. According to Ge et. al. (2006), residential or housing choice at some extend also represents a preferred lifestyle. Consumers are therefore going to buy property in line with their lifestyle. Mobility is a fundamental process in shaping urban and regional settings. Housing studies also is a study on how housing and mobility intersect. Mobility associated with maximizing financial wellbeing and quality of life becomes a significant factor in the housing locational choice of the residents (Howley et. al., 2008). Moreover, people weigh in their decision-making system both the quality of the house and the neighbourhood (Clark et. al., 2006). Kauko (2006, 2007) emphasized that housing locational factors are the essential factor considered by the housing consumers than the housing unit itself. In the process of community development, the physical built environment along with a sense of neighbourhood factor is fundamental. The vitality is not only to the community entirely but also to individual residents in any community for their personal development (Li, 2007). In relevance according to Montgomery and Curtis (2006) a variety of pull and push factors that influence the housing choice of between whether to move or stay. This article focuses on three (3) major factors of housing decision or the choice of preferences between house, location, or neighbourhood in detail by each category of Malaysian generations.

\section{METHODOLOGY}

For this study, mixed methods strategy were used with combinations of qualitative and quantitative approaches. As stated by Creswell (2006) and Creswell and Plano (2007), the study on mixed techniques is designed to collect, analyze and combine quantitative and qualitative study/data in a single study or series of studies to comprehend a study issue. Since housing decisions and choices are consumer behavioural studies, the adoption of mixed methods in this study which determines the housing choice between house, location, or neighbourhood by generations is regarded the best method to be used. According to Cresswell (2009), the mixed method provides benefits that provide a better knowledge of study issues than either strategy alone. The three (3) main data collection methods in survey study comprises of interviewing, administering a questionnaire, and observing people and phenomena (Sekaran and Bougie, 2010). Therefore, interviews with the local authorities and housing developers in Selangor were conducted for this study. This is to show demographics (population) as the main factor to be considered in property development principally for housing provision that strongly relates to demand and supply for housing. The quantitative data through survey questionnaires to the housing consumers were much needed in determining the Malaysian generations choices of residential environment preferences. The quantitative data were gained through a convenience sampling strategy. A sum of 1,067 respondents corresponded via several survey methods including dropoff, face-to-face interview, postal interview, and internet survey (web-survey).

This study employed three (3) stages of data analyses. The first stage is The Descriptive Analysis Techniques through the assistance of Excell and SPSS. The second stage of analysis is through The Comparison Analysis which is also known as The Pair-wise Method. Finally, The Analytic Hierarchy Process (AHP) method was adopted in the third stage. The data were firstly analysed by using the Excell and SPSS 16.0 software package in obtaining basic and general statistical indications for the study. Then, Paired Comparison (Pair-wise) a descriptive technique were applied to obtain the comparative significance of housing decision on the choices between house, location or neighbourhood as a key attraction factor for housing. Former studies on housing identified the location as among of the most significant factor influencing house purchasing decision-making process of an individual (Daly et al., 2003; Kaynak and Stevenson, 2007; Sengul et al. 2010; Xiao and Tan, 2007). House features are revealed to have an important relationship with the intention to buy a house (Chia et. al. 2016). According to Tan Teck-Hong (2011), people are willing to spend more of their money for a house with good environment qualities and hence located in a good neighbourhood. The Pair-wise method was adopted in obtaining house buyer decisions on the choice between house, location or neighbourhood. Here, the respondents were made to choose one from two (2) given choices of housing factor at a time. The findings on the choices made were described by the higher percentage shown in the data analysis results. In the Pair-wise method, a score for maximum and minimum response was assigned in the analysis to show how much more significant one choice as compared to the other given choice. The values derived from the analysis were then translated into the percentage of the total score. This were done in gaining better interpretation of the relative importance of the choices made. The Pair-wise method is a method of examining questions with the use of scaling technique. Therefore, the adaptation of the Pair-wise in housing decisions in determining the most important housing choice by the Malaysian generation it is considered best to adopt the method in this study. According to Kumar et. al. (2013), the comparative scales and non-comparative scales are the techniques used in various scaling method studies. In a comparative rating scale, the respondents were required to evaluate (assign a value) to a particular item/brand/product in comparison to other items/brands/products and the evaluation cannot be possible without comparison. In addition, the Analytic Hierarchy Process (AHP) method was adopted in the final stage of the analysis for this study. The application of AHP has been found in several other studies as in planning. According to Validya 
and Kumar (2006), this method provide assistance in selecting the best choice, provisions of resource, conflict resolution, optimization, and numerical extensions. Wu (2010) agrees that the AHP method as a Multi-attribute or multiple elements modelling which is an appropriate method for non-monetary value assessment.

Amounts of housing consumer and behavioural studies adopted the Analytic Hierarchy Process (AHP) method (Kauko, 2006, 2007; Wu, 2010). In relevance, the use of AHP in built environment studies has been comprehensively used including on housing issues on discussions concerning housing selection, and housing quality in specific. The AHP method was essentially implemented in housing decisions in the housing choices that allows decision-makers to link the subjective and objective factors engaged in the multi-criteria decision. Wu (2010) who also observed and agrees that the Analytical Hierarchy Process (AHP) provide a straightforward and useful technique to ascertain the suitable weighting of various environmental characteristics. The employment of Pair-wise together with the AHP method or technique is therefore regarded as the best technique to be used to determine Malaysian generations' housing choices and decisions.

\section{MAIN FINDINGS AND DISCUSSION}

The qualitative data procured in this study was done by means of interviews with local authorities and housing developers in the state of Selangor. The series of interviews with the local authorities and housing developers as the main actors of property development disclosed that the population in this study refers to the generations was found as the prime factor to be considered in the planning for housing. The inclusion of population data by the housing developers in their housing development conversely is very general. The data on populations were only used for the purpose mainly in determining the market and feasibility or the market demand and viability of the proposed development. Furthermore, the absence of the population data in the study was not in specific by generations or by different age group. The simple survey conducted by the housing developers were only to determine general preferences to indicate the demand for the housing project to be developed.

Hence, this shows the necessities of this study of housing decisions determination by the Malaysian generations on the prime housing decision that is choice made between house, location or neighbourhood. Besides, the quantitative data obtained from the Malaysian generations of housing consumers were analysed through three (3) stages of data analyses; $1^{\text {st }}$ stage via SPSS; $2^{\text {nd }}$ stage via Paired Comparison Analysis (Pair-wise method); and $3^{\text {rd }}$ stage via Analytical Hierarchy Process (AHP) Method. The application of Pairwise method was significant in determining the most and least preferred housing choice between location, neighbourhood, and house based on three (3) pairs of choices. The $1^{\text {st }}$ pair of housing choice is between location and house. The $2^{\text {nd }}$ pair of housing choice is between location and neighbourhood and finally the $3^{\text {rd }}$ pair of housing choice is between house and neighbourhood.

Table 1: The future housing choice preference (main attraction factor) by using SPSS

\begin{tabular}{lc}
\hline \multicolumn{2}{c}{ SPSS } \\
\hline Attraction factor & Level of importance (per cent) \\
\hline Location & 66.7 \\
House & 33.3 \\
Neighbourhood & 0.0 \\
\hline
\end{tabular}

Table 2: The future housing choice preference (main attraction factor) by using Pairwise Method

\begin{tabular}{lcc}
\hline \multicolumn{3}{c}{ THE PAIRWISE METHOD } \\
\hline \multicolumn{1}{c}{ Pair } & Most preferred & Per cent \\
\hline Location vs. House & Location & 63.9 \\
Location vs. Neighbourhood & Location & 56.5 \\
House vs. Neighbourhood & House & 64.2 \\
\hline
\end{tabular}

Table 1 shows the results of the $1^{\text {st }}$ stage of analysis by using SPPSS on future housing choice preferences (main attraction factor). In general, the majority of the respondent perceived location (66.7 per cent) as the main attraction choice factor for future housing followed by the house (33.7 per cent). By contrast, the respondents did not consider the neighbourhood in the first round of the analysis (using SPSS) to be at all one of the preferred factors for future housing choice. 
The $2^{\text {nd }}$ stage of analysis was done through Pair-wise Method (Table 2). For the 1st pair of given option Location versus House, most respondents chose the location $(63.9 \%)$ as their prime attraction factor of choice for future housing. Interestingly, for the $2^{\text {nd }}$ pair of a given option of Location versus Neighbourhood, majority of the participants still choose the location (56.5 per cent) as their main attraction factor for future housing, However, in the $3^{\text {rd }}$ pair of given option House and Neighbourhood, the respondent chose House (64.2 per cent) over Neighbourhood.

The prime attraction choice for future housing was then further analysed in the $3^{\text {rd }}$ analysis by using the Analytic Hierarchy Process (AHP Method) a method commonly used in consumer decision making (Table 3). The AHP technique was introduced in this stage together with the use of Pair-wise in weighing the future housing choice in detail by generations.

The AHP method employed in this study consist of five (5) point of scales questionnaire with choices of preferences; "Indifferent", "Weakly prefer", "Considerably prefer", "Strongly prefer" or "Absolutely prefer" along with the real input based on pair-wise weights from 1 to 5 . The weighting findings of each housing choice factor produced from the 43 eligible ( 95 per cent) showed consistency outcomes equaivalent to or below 0.1 whereas 409 showed inconsistency of outcomes above 0.10 .

Table 3: The future housing choice preference (main attraction factor) Results of Consistency Ratio Index - Analytic Hierarchy Process (AHP)

\begin{tabular}{|c|c|c|c|c|}
\hline No & Location & House & Neighbourhood & CR \\
\hline 1 & 0.609 & 0.120 & 0.272 & 0.060 \\
\hline 2 & 0.097 & 0.620 & 0.284 & 0.073 \\
\hline 3 & 0.097 & 0.620 & 0.284 & 0.073 \\
\hline 4 & 0.104 & 0.665 & 0.231 & 0.073 \\
\hline 5 & 0.620 & 0.284 & 0.097 & 0.073 \\
\hline 6 & 0.557 & 0.122 & 0.320 & 0.013 \\
\hline 7 & 0.106 & 0.634 & 0.260 & 0.029 \\
\hline 8 & 0.097 & 0.620 & 0.284 & 0.073 \\
\hline 9 & 0.609 & 0.272 & 0.120 & 0.060 \\
\hline 10 & 0.360 & 0.127 & 0.512 & 0.090 \\
\hline 11 & 0.648 & 0.122 & 0.229 & 0.000 \\
\hline 12 & 0.634 & 0.260 & 0.106 & 0.029 \\
\hline 13 & 0.634 & 0.260 & 0.106 & 0.029 \\
\hline 14 & 0.634 & 0.260 & 0.106 & 0.029 \\
\hline 15 & 0.120 & 0.609 & 0.272 & 0.060 \\
\hline 16 & 0.106 & 0.634 & 0.260 & 0.029 \\
\hline 17 & 0.581 & 0.309 & 0.109 & 0.000 \\
\hline 18 & 0.106 & 0.634 & 0.260 & 0.029 \\
\hline 19 & 0.097 & 0.620 & 0.284 & 0.073 \\
\hline 20 & 0.097 & 0.620 & 0.284 & 0.073 \\
\hline 21 & 0.104 & 0.665 & 0.231 & 0.073 \\
\hline 22 & 0.620 & 0.224 & 0.155 & 0.090 \\
\hline 23 & 0.097 & 0.620 & 0.284 & 0.073 \\
\hline
\end{tabular}

\begin{tabular}{|l|l|l|l|l|}
\hline 24 & 0.260 & 0.106 & 0.634 & 0.029 \\
\hline 25 & 0.104 & 0.665 & 0.231 & 0.073 \\
\hline 26 & 0.097 & 0.620 & 0.284 & 0.073 \\
\hline 27 & 0.106 & 0.634 & 0.260 & 0.029 \\
\hline 28 & 0.104 & 0.665 & 0.231 & 0.073 \\
\hline 29 & 0.102 & 0.532 & 0.366 & 0.082 \\
\hline 30 & 0.613 & 0.267 & 0.121 & 0.038 \\
\hline 31 & 0.360 & 0.127 & 0.512 & 0.090 \\
\hline 32 & 0.346 & 0.110 & 0.544 & 0.046 \\
\hline 33 & 0.346 & 0.110 & 0.544 & 0.046 \\
\hline 34 & 0.634 & 0.260 & 0.106 & 0.029 \\
\hline 35 & 0.198 & 0.312 & 0.490 & 0.046 \\
\hline 36 & 0.360 & 0.127 & 0.512 & 0.090 \\
\hline 37 & 0.360 & 0.127 & 0.512 & 0.090 \\
\hline 38 & 0.224 & 0.620 & 0.155 & 0.090 \\
\hline 39 & 0.334 & 0.141 & 0.525 & 0.040 \\
\hline 40 & 0.620 & 0.224 & 0.155 & 0.090 \\
\hline 41 & 0.272 & 0.120 & 0.609 & 0.060 \\
\hline 42 & 0.609 & 0.120 & 0.272 & 0.060 \\
\hline 43 & 0.634 & 0.106 & 0.260 & 0.029 \\
\hline CR: Consistency Ratio Index & & \\
\hline
\end{tabular}

Table 4: The future housing choice - preferred attraction factor by using AHP Method

\begin{tabular}{lll}
\hline THE AHP METHOD & & \\
\hline Factor & Mean factor weight & Rank \\
\hline Location $(n=43)$ & 0.3353 & $\mathbf{2}$ \\
House $(n=43)$ & 0.3701 & $\mathbf{1}$ \\
Neighbourhood $(n=43)$ & 0.2947 & $\mathbf{3}$ \\
\hline
\end{tabular}

Table 5: The future housing choice - preferred attraction factor by Gender

\begin{tabular}{lcccc}
\hline \multirow{2}{*}{ Factor } & \multicolumn{3}{c}{ Group mean factor weight } \\
\cline { 2 - 5 } & $\begin{array}{c}\text { Male } \\
(n=15)\end{array}$ & Rank & $\begin{array}{c}\text { Female } \\
(n=30)\end{array}$ & Rank \\
\hline Location & 0.4044 & $\mathbf{1}$ & 0.3019 & $\mathbf{3}$ \\
House & 0.2736 & $\mathbf{3}$ & 0.4167 & $\mathbf{1}$ \\
Neighbourhood & 0.3221 & $\mathbf{2}$ & 0.3344 & $\mathbf{2}$ \\
\hline
\end{tabular}


Table 6: The future housing choice - preferred attraction factor by Generations

\begin{tabular}{lcccccccc}
\hline & \multicolumn{9}{c}{ Group mean factor weight } \\
\cline { 2 - 9 } \multicolumn{1}{c}{ Factor } & $\begin{array}{c}\text { Baby } \\
\text { Boomer } \\
(n=3)\end{array}$ & Rank & $\begin{array}{c}\text { Generation } \\
\text { X } \\
(n=10)\end{array}$ & Rank & $\begin{array}{c}\text { Generation } \\
\text { Y }\end{array}$ & Rank & $\begin{array}{c}\text { Generation } \\
\text { Z } \\
(n=24)\end{array}$ & Rank \\
\hline Location & 0.4063 & $\mathbf{2}$ & 0.3008 & $\mathbf{3}$ & 0.3638 & $\mathbf{2}$ & 0.2433 & $\mathbf{3}$ \\
House & 0.1610 & $\mathbf{3}$ & 0.3460 & $\mathbf{2}$ & 0.3952 & $\mathbf{1}$ & 0.4143 & $\mathbf{1}$ \\
Neighbourhood & 0.4330 & $\mathbf{1}$ & 0.3533 & $\mathbf{1}$ & 0.2410 & $\mathbf{3}$ & 0.3428 & $\mathbf{2}$ \\
\hline
\end{tabular}

Table 4 presents the summary of examined average factor weights of future housing choice preferred attraction factors by comparisons between location, house, and neighbourhood. The findings generally indicate house as the $1^{\text {st }}$ choice $\left(1^{\text {st }}\right.$ rank) or mostly preferred factor for future housing choice. The location was chosen as their $2^{\text {nd }}$ selection $\left(2^{\text {nd }}\right.$ rank) of the preferred factor. The neighbourhood was selected as their last choice (rank -3$)$. On the other hand, when these pairs of choices (location vs. house, location vs. neighbourhood and house vs. neighbourhood) (Table 5) were analyzed and compared by gender and the outcomes differed by ranks across generations. The factor of location was perceived as the prime attraction factor of future housing choice by the male or chosen as the $1^{\text {st }}$ rank of importance. Neighbourhood was chosen as the $2^{\text {nd }}$ rank) and house as the $3^{\text {rd }}$ rank of preferred housing choice by the male. In contrast, Table 6 shows the future housing choice of preferred attraction factor in detail among the generations. The future housing choices made by the Baby Boomers in the ranking were: $1^{\text {st }}$ Ranking Neighbourhood, $2^{\text {nd }}$ Ranking - Location and $3^{\text {rd }}$ Ranking - House. Gen-X also put Neighbourhood as their $1^{\text {st }}$ rank of preferred choice same ranking as the Baby Boomers. The differences of preferred choice between the Baby Boomers generation and Gen-X were found on the $2^{\text {nd }}$ and $3^{\text {rd }}$ rank of preferred choices; Rank 2 - House and Rank 3 - Location. Besides, Gen-Y and Gen-Z as younger generations show a similar pattern of preferred future housing choice ranking whereby both generations ranked House as their $1^{\text {st }}$ rank of preferred choice. The differences of preferences were found on the factor of Location which was ranked as $2^{\text {nd }}$ ranked of option b Gen-Y and ranked as the $3^{\text {rd }}$ ranked of preferred choice by Gen-Z. Meanwhile, the Neighbourhood was ranked as the $3^{\text {rd }}$ choice of the preferred factor of future housing and $2^{\text {nd }}$ by Gen-Z. The housing decision on the choice made was induced primarily by either spouse, partner, husband or wife and either by the family or family members.

Table 7: The future housing choice - preferred attraction factor by using Paired Comparison Analysis (Pair-wise) and Analytical Hierarchy Process (AHP)

\begin{tabular}{lcccc}
\hline & \multicolumn{2}{c}{$\begin{array}{c}\text { Paired Comparison Analysis } \\
\text { Factor }\end{array}$} & \multicolumn{2}{c}{ Analytical Hierarchy Process (AHP) } \\
& (Pair-wise) & & & \\
\cline { 2 - 5 } & Importance (percent) & Rank & Mean factor weight & Rank \\
\hline Location $(n=43)$ & 66.7 & $\mathbf{1}$ & 0.3353 & $\mathbf{2}$ \\
House $(n=43)$ & 33.3 & $\mathbf{2}$ & 0.3701 & $\mathbf{1}$ \\
Neighbourhood $(n=43)$ & 0.0 & 3 & 0.2947 & 3 \\
\hline
\end{tabular}

The worthy findings derived form this study is on the results of analysis derived from the adopted method through SPSS and Pair-wise (Table 7) which show similarity in the future housing choice preferred attraction factor. Through Pair-wise analysis, the location was perceived as primarily important and ranked as the $1^{\text {st }}$ choice followed by the house as the $2^{\text {nd }}$ rank of choice. With the AHP, the house was ranked as 1 st choice and location as $2^{\text {nd }}$ rank of choice. However, both analyses show similar results with the neighbourhood as the $3^{\text {rd }}$ rank of choice for future housing.

While results from Pair-wise and AHP show that location and house was ranked as either $1^{\text {st }}$ and $2^{\text {nd }}$ in the analysis separately, this results can also be regard as valid and significant. This is because the derived results from via SPSS and Pair-wise methods constantly show the location and house both are the prime preferred attraction for future housing choice ranked as the top 2 preferred housing choice factor. The summary of the overall finding for this study is presented in Figure 3. 


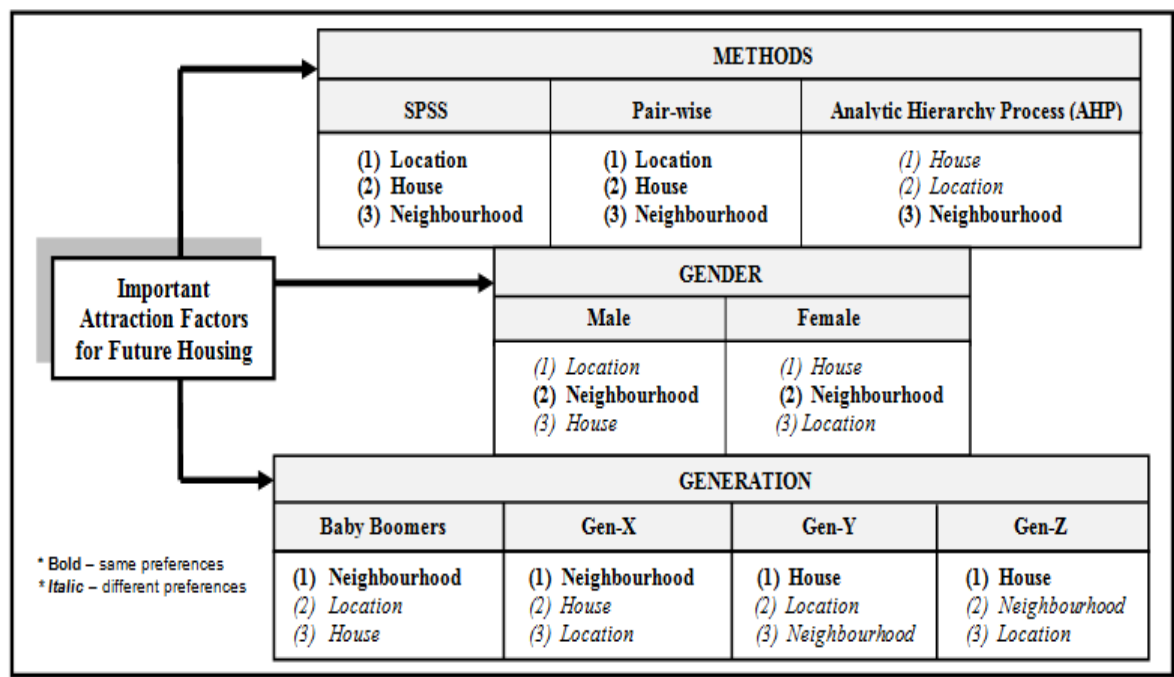

Figure 3: Summary of Findings of the future housing choice - preferred attraction factor

Differences of preferred attraction factor for future housing choice between generations found in this study indicates that the generations were equipped with different needs and thus reflect divergence or differences of preferences. The housing choice preferences between older generations (Baby Boomers and Gen-X) and younger generations (Gen-Y and Gen-Z) were different due to the age gaps between the two. However, this study shows that the older generations namely Baby Boomers and Gen-X both share the same housing choice preferences where both generations regard Neighbourhood as their $1^{\text {st }}$ ranked of attraction factor for future housing. The younger generations such as Gen-Y and Gen-Z both perceived House (Rank-1) as their prime factor for future housing choice.

Type of gender also depicts differences in housing choice preferences. The location was perceived as the prime future housing choice attraction factor preferred by the males. The neighbourhood, in contrast, was chosen as the most important factor to be considered for future housing by the females. Özturk and Ceylan (2016) stressed that the differences of preferences by genders (male and female) makes it necessary for them to consider the products and positioned differently before making decision to purchase. This is because males and females desire different products and therefore they are likely to have different behaviours or fancy and thus dissimilar actions of gaining these (Mitchell and Walsh, 2004). In consumer behaviour studies, gender is one of the main factors that show great differences in term of preferences. The expectations, wants, needs, preferences, and life-style were different by genders and this signifies their consumption behaviours. According to Siddiqui (2016), in consumer behaviour for example in purchasing decisions women were perceived as generally make decisions with more influenced by emotion as compared to men that will normally go more with rationals based on the facts and data before making a purchasing decision.

\section{CONCLUSION}

In consumer behaviour, decision making is about the range of selection between choices of alternatives. The choices made between best alternatives can be shown by the results derived from the Pair-wise and AHP method as the prime method in understanding consumer behaviour. This article provides an in-depth overview on the Malaysian housing consumers' decision-making on the preferred housing choices by generations namely the Baby Boomers, Gen-X, Gen-Y, and Gen-Z. The main future attraction factors for housing were based on the three (3) main housing choices or alternatives of preferences between house, location or neighbourhood. The Pair-wise and Analytic Hierarchy Process (AHP) methods adopted in this study was considered as the best method to be used as in determining the Malaysian generations' preferred factor for future housing choice and thus provide some understanding on housing consumer behaviour.

The findings from this study disclose housing choice preferences differences specifically by generations or known as the generational differences. The study also shows genders differences of preferences on housing decision or choices of future housing attraction factor made between location, house and neighbourhood. 
The Baby Boomers generation and Gen-Y choice of the neighbourhood as the prime factor for future housing show some indication of great appreciation on community and sense of belonging required by the older generations for any residential environment. This is because the Baby Boomers were regarded as the empty nesters, preferring to be independent and stay in the same housing environment where they have spent the most years of their age (the same neighbourhood). Meanwhile, the younger generations as the Gen-X and Gen-Z choice of future housing preferences on the house factor indicates that the younger generations appreciate the physical factor more compared to the sense of attachment or sentimental value.

Therefore, the findings of this study give implication in providing reason on the needs for specifically tailored housing policies by generations or according to different age groups. On the other hand, the continuous number of population growth in Malaysia especially the elderly (seniors) generations demand for another specialized housing concept for the generation as the new group of prospect housing buyer which equipped with unique characteristics and thus specific housing needs. The concept of Elderly (Senior) housing in Malaysia is quite as compared to other developing countries. More study is needed to cater to the elderly housing consumer needs and preferences which should be focussed to as the next prospective buyer which financially stable. Therefore, various types of Elderly (Senior) housing concepts should be introduced and made available for better housing options. For example, the Multi-generational housing concept with the inclusion of Elderly-Friendly features in every housing environment in Malaysia would be great in promoting the active-ageing concept and thus assist the elderly to agein-place without separating the elder and younger generations in different types of housing whereby all generations living together but at the same time living independently.

The Gen-Y and Gen-Z the younger generations which found in this study who perceived house as their prime future housing choice factor is mainly because as the $1^{\text {st }}$ timer of own household formation, $1^{\text {st }}$ marriage, leaving parental/family house, having own house (rental or owner-occupied) is necessary and be set as their key priority. Therefore, the house itself physically was set as their $1^{\text {st }}$ rank of future housing choice factor as compared to the neighbourhood. For the younger generations, with the limitation of financial capability as long as they can afford to buy the house, the neighbourhood is the $2^{\text {nd }}$ criteria to be considered for future housing. The other possible reason is may be because the younger generations regard the physical features of the house itself is more important that the sense of community/neighbourhood belonging. Consequently, the avalilibity of more housing provisions which is affordable to be owned or consumed by the younger generations is vital. Various parties especially the main actors of property development as the prime supplier of housing have to work together in supporting and assisting the younger generations to able them to consume their $1^{\text {st }}$ house although with limitation of financial capability. The needs for affordable housing is very significant especially for the younger generations in the urban area. In fact, there were still Malaysian generations who are still struggling in owning a house although with combine household income.

In conclusion, the findings of this study show generational differences or differences of preferences in the decision or choice for future housing. The future housing choice preferences by generations were made by considering the prime factor between location, house and neighbourhood. It was found that, the older generations (Baby Boomers and Gen-X) appreciate the neighbourhood and sense of belonging with the community more that the younger generations (Gen-Y and Gen-Z) who regard the house as the main choice for future housing. Finally, the use of Pairwise and AHP methods were still considered as the best method in understanding the consumer behaviour including in determining housing decision or preferred future housing choice factor in detail by generations.

\section{ACKNOWLEDGEMENT}

The authors would like to thank The Institute of Research, Management and Innovation (IRMI), Universiti Teknologi MARA (UiTM) for the award of funding for this study under the Lestari Grant 2018 (600-IRMI 5/3/LESTARI).

\section{REFERENCES}

Ademiluyi, A.I. (2010), 'Public housing delivery strategies in Nigeria: a historical perspective of policies and programmes', Journal of Sustainable Development in Africa, Vol. 12 No. 6, pp. 153-161, Clarion University of Pennsylvania, Clarion, PA

Bujang, A. A., Zarin H. A. and Jumadi, N. (2010) 'The Relationship between Demographic Factors and Housing 
Affordability’ The Malaysian Journal of Real Estate, Vol.5, No.1

Chia, J., Harun, A., Kassim, A.W.M., Martin, D. and Kepal, N. (2016) 'Understanding Factors That Influence House Purchase Intention Among Consumers in Kota Kinabalu: An Application of Buyer Behaviour Model', Journal of Technology Management and Business Theory’ Vol 03, No 02, 94-110

Clark, W.A.V., Deurloo, M.C. and Dieleman, F.M. (2006) 'Residential mobility and neighbourhood outcomes'. Housing Studies, 21(3), 323-342

Creswell, J. W., \& Plano, Clark, V. L. (2007). Designing and conducting mixed methods research. Thousand Oaks, CA: Sage

Creswell, J.W. (2009). Research Design Qualitative, Quantitative and Mixed Methods Approaches. California: SAGE Publications, Inc.

Daly, J., Gronow, S., Jenkins, D., \& Plimmer, F. (2003). Consumer behaviour in the valuation of residential property: A comparative study in the UK, Ireland and Australia. Property Management, 21(5), 295-314.

Dodoo, J. (2007) 'Practical Approach Towards Buyer Behaviour' unpublished thesis Atlantic International University, Hawaii, USA, September 2007

Gajjar, N. B., (2013) 'Factors Affecting Consumer Behaviour' Journal of Research in Humanities and Social Sciences, Vol.1 No.4 pp. 10-15

Ge, J., Chen, F., Wang, J. and Hokao, K., (2006) 'Residential environment model considering residential preferences in Changjiang Delta Region of China' International Symposium of Lowland Technology September 14-16 2006, in Saga, Japan.

Golubchikov, O. \& Badyina, A. (2012). Sustainable housing for sustainable cities: a policy framework for developing countries. Nairobi, Kenya: UN-HABITAT.

Howley, P., Scott M. and Redmond, D. (2008) 'An Examination of Residential Preferences for Less Sustainable Housing’ RERC Working Paper Series PUT 08-WP-RE-24, Web: www.tnet.teagasc.ie/rerc/

Hurtubia, R., Gallay, O., \& Bierlaire, M. (2010) 'Attributes of households, locations and real-estate markets for land use modelling'. SustainCity Deliverable, 2, 1-27.

Kauko, T. (2006), "What makes a location attractive for the housing consumer? Preliminary findings from metropolitan Helsinki and Randstad Holland using the analytical hierarchy process", Journal of Housing and the Built Environment, Vol. 21 No. 2, p. 159

Kauko, T. (2007), “An analysis of housing location attributes in the inner city of Budapest, Hungary, using expert judgements”, International Journal of Housing Policy, Vol. 6, No. 1, pp. 77-99

Kaynak, E., \& Stevenson, L. (2007). Comparative Study of Home Buying Behaviour of Atlantic Canadians. Home Buying Behaviour, 3-11.

Kim, T.K., Horner, M.W. and Marrans, R.W. (2005), 'Life cycle and environment factors in selecting residential and job locations', Housing Studies, Vol. 20, pp. 457

Kotler, P. T., Keller, K. L. Marketing Management 14th Edition. (2012). Upper Saddle River: Prentice Hall. p. 816.

Kumar, M., Talib. A. S. and Ramayah, T. (2013), 'Business Research Methods'. Oxford University Press, Malaysia

Lachman, M. L. (2010) Generation Y: America’s new housing wave, Gen, 10, pp. 33-45

Li, Ling-Hin, (2007) 'The physical environment and a sense of neighborhood in residential communities in Hong Kong' Journal of Property Management, Vol. 26 No. 1, pp. 7-24 
Livette, M. (2006) 'A marketing perspective of private sector retirement housing and the effectiveness of the buyer behavior of its purchasers' Emerald Property Management, Vol. 24 No.4, pp.383-396

Livette, M. (2006) 'Retirement housing for sale and differences in the decision to purchase that are determined by gender or marital status' Property Management, Vol. 24, No.1. pp. 7-19.

Montgomery, M., and Curtis, C., (2006) 'Housing Mobility and Location as Choice: A Review of the Literature' Urbanet Planning Department of Urban and Regional Planning Curtin University. $\underline{\text { http://urbanet.curtin.edu./au }}$

Mulder H. C. (2006) 'Population and housing: A two-sided relationship' Journal of Demographic Research, Vol.15, pp. $404-412$

Özturk, A. and Ceylan, E. (2016) 'A Study Towards Identifying the Tendencies of the Female Consumers Working in Public Sector to Online Shop' International Journal of Scientific and Research Publications, Volume 6, Issue 7, July 2016, pp.568-574

Sanchez, TW \& Dawkins, CJ 2001, 'Distinguishing City and Suburban Movers: Evidence from the American Housing Survey ', Housing Policy Debate, vol. 12, No. 3, pp. 607-31.

Sekaran, U. and Bougie, R. (2010), "Research Methods for Business A Skill Building Approach 5 ${ }^{\text {th }}$ Edition", John Wiley \& Sons Ltd., United Kingdom

Sengul, H., Yasemin, O., \& Eda, P. (2010) 'The assessment of the housing in the theory of Maslow's hierarchy of needs'. European Journal of Social Sciences, 16(2), 214-219.

Siddiqui, W. (2016) 'Study on Buying Behavior of Men and Women', Imperial Journal of Interdisciplinary Research (IJIR) Vol-2, Issue-4(2016), pp. 664-667

Skaburskis, A. (2002) 'Generational Differences and Future Housing Markets' Canadian Journal of Regional Science XXV:3 (Autumn 2002), pp.377-404

Tan, T. H. (2011) 'Neighborhood preferences of house buyers: the case of Klang Valley, Malaysia', International Journal of Housing Markets and Analysis, Vol. 4 Issue: 1, pp.58-69

Tan, T. H. (2012) 'Meeting first-time buyers' housing needs and preferences in greater Kuala Lumpur, Cities', 29(6), pp. 389-396.

Tan, T. H. \& Khong, K. W. (2012) 'The link between homeownership motivation and housing satisfaction'. International Journal of Economics and Management, 6(1), pp. 1-20.

Vaidya, O.S. and Kumar, S. (2006), "Analytic hierarchy process: an overview of applications", European Journal of Operational Research, Vol. 169, p. 1

Wang, D. \& Li, S. M. (2006) 'Socio-economic differentials and stated housing preferences in Guangzhou, China'. Habitat International, 30(2), pp. 305-326

Wu, F. (2010) 'Housing environment preference of young consumers in Guangzhou, China', Journal of Property Management, Vol. 28 No. 3 pp. 174-192

Xiao, Q., \& Tan, G. (2007) 'Signal extraction with Kalman filter: A study of the Hong Kong property price bubbles'. Urban Studies, 44(4), 865-888

Zwarts, A. and Coolen, H. (2006) 'The Meaning of Preferences for Residential Environment Features: A Case Study Among Apartment Dwellers in The Netherlands', Journal of Architectural and Planning Research 23:3 (Autumn, 2006)

Zyed, A.S.Z, Wan, N.A. and Hanif, N.R. (2016) 'Housing Affordability Problems among Young Households', Journal of Surveying, Construction and Property (JSCP). Vol 7 pp. 1-18. / http://e-journal.um.edu.my/publish/JSCP/ 